\title{
Research on Entrepreneurial Management Mode of New High-Tech Enterprise
}

\author{
JI Shunhong \\ School of Economic Management, Nanjing University of Science and Technology \\ jishunhong889@163.com
}

\begin{abstract}
Keywords: New high-tech enterprise; Entrepreneurial management; Mode
Abstract. Enterprise management mode shows brand-new changes with constant deepening of reform and opening up in China and rapid development of market economy. Enterprise management mode has certain particularity itself especially for new high-tech enterprises. It faces many risks and potential risks in the management process. However, entrepreneurial management stage is regarded as an important link in new high-tech enterprise development process, which should be emphasized highly and has remarkable significance for enterprise development. In the paper, the author starts from many aspects in the research process. Characteristics of new high-tech enterprises are combined for describing the necessary of perfecting entrepreneurial management mode of new high-tech enterprises in China currently. Related mode and strategies of new high-tech enterprise entrepreneurial management are proposed aiming at corresponding problems. It is expected that the mode and strategies can play certain reference role to certain extent.
\end{abstract}

\section{Introduction}

In recent years, new high-tech enterprises bring significant impact to China's economic development, governments and related departments thereof issue relevant supporting policies, good environment is created for new high-tech enterprise development, thereby optimizing and perfecting innovation entrepreneurial environment in an unprecedented mode, and establishing confidence of entrepreneurs to achieve entrepreneurial success. Entrepreneurs should grasp policy opportunities firmly for perfecting entrepreneurial management mode constantly and achieving ultimate goals of entrepreneurship.

\section{Necessity of perfecting entrepreneurial management mode of new high-tech enterprises}

\section{Being beneficial for benign competition of new high-tech enterprises}

In recent years, the quantity of new high-tech enterprises shows significant increasing trend under vigorous support of policies in China, new high-tech enterprises have increasingly intense competition especially with inspection of some excellent talents at home and abroad. However, it is undeniable that there are still some blind entrepreneurial behaviors. Some enterprises are trapped into vicious competition. Perfection of management mode should correspond to current market development needs for entrepreneurs. Virtuous development of enterprises also can be realized.

\section{Requirement of innovative thinking for new high-tech product features}

New high-tech products have own features compared with products in other types, the most obvious feature is higher risk. The risk is reflected in both high investment on the product itself and sales return risk. Even if higher cost is invested in the product development process, anticipated returns can not be obtained under mot circumstances. Therefore, product sales demand of new high-tech enterprises can be met through perfection of entrepreneurial management mode. Risk expansion can be avoided from many aspects. 


\section{Analysis on present situation of new high-tech enterprise entrepreneurial management}

\section{Present situation of new high-tech enterprise entrepreneurial management}

Both technology development field and market demand technological development hotspot always keep consistent according to current entrepreneurship field of new high-tech enterprises in China as shown in the following figure.

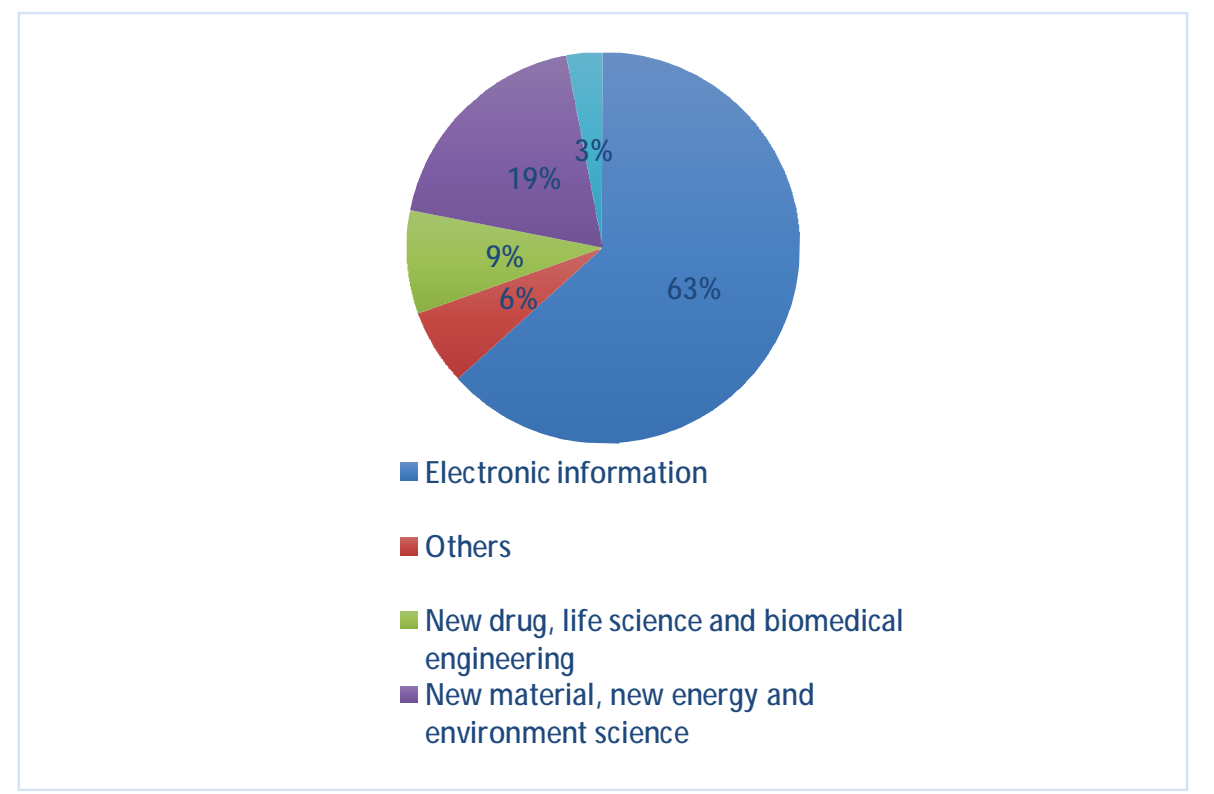

Figure 1 Technology field structure of high and new high-tech enterprises

The above pie chart shows that entrepreneurial technology field of new high-tech enterprises is tightly connected with market demand. However, enterprises can achieve larger development from the objective point of view under fierce market competition environment. It can be concluded that market is the original power of technological innovation. Competition makes enterprises to produce more urgent requirements on technological innovation.

\section{Problems in new high-tech enterprise entrepreneurial management}

\section{Limitation on understanding of technology innovation management}

High-tech enterprise daily management shows that it has certain influence on enterprise development strategy and planning, marketing and technical service guarantee, etc. Some enterprises set up special development department under the support role of sufficient assets, the development departments are responsible for improvement and updating of enterprise products. However, current situation shows that products of many new high-tech enterprises are lack of innovation and appeal. Related data show that only $22 \%$ of the new high-tech enterprises fully realize product innovation in China; the vast majority of enterprises select the form of copy and imitation at the start-up stage. It is possibly related to development background and environment of some enterprises in China and existing system and policy in China directly.

In addition, new high-tech enterprise entrepreneurs always have technical background. Therefore, they believe that the power of technology cannot be ignored in the thought idea. However, some people tend to high-tech products from the objective point of view, and the population is analyzed. It is obvious that such people often belong to innovators. However, market scale should be monitored more importantly. Currently, high-tech entrepreneurial enterprises have one obvious problem that technical personnel blindly occupy dominant position. Market conditions are not studied and analyzed aiming at market condition. New technology is developed and introduced blindly, thereby wasting resources greatly. Current market environment in China has a gradient aiming at technology demand. 
Understanding of customers on technology is extremely effective. Technology propaganda is one important task aiming at government and enterprises; thereby customers can comprehend the market.

\section{Over-consistency with principle of product supremacy}

New high-tech enterprise entrepreneurs are lack of promotion planning in the process of product development, some enterprises are prominently insufficient in the aspect of resources, which still have one-sided pursuit of 'large and comprehensive' product line. Such enterprises can not give equal attention to all details. Many enterprises focus on whether own product quality reaches standards or not due to the limitation of the concept rather than treating market demand correctly. Enterprises have been trapped into the trouble at the beginning of entrepreneurship.

\section{Lagged marketing method}

The new high-tech product marketing needs are combined with characteristics of products and services. However, marketing mode of many new high-tech enterprises can't be combined with characteristics of products currently. Some enterprises have one-sided pursuit of marketing results and constantly stir up some vague concepts, thereby trying to get more attention especially under the background of the current Internet high-speed development. However, some enterprise promotion is different from products. Product sales are greatly fluctuated, thereby leading to obvious risk and potential risks as a result. In addition, some enterprises invest excessive fund on advertisement propaganda and media speculation. Therefore, product development and technology updating can not be supported correspondingly. Currently, there is more serious homogeneity phenomenon in China market, and more similar products and enterprises are available. The phenomenon is produced due to lag and improper marketing methods as an important reason. Enterprises will suffer from bad market competition for long term; thereby it is also not beneficial for long-term development of the enterprises.

\section{Countermeasure to perfect entrepreneurial management mode of new high-tech enterprises}

\section{Information construction and development}

It can not be denied that new high-tech enterprise itself is connected with informatization in many aspects. Therefore, information tools should be utilized for showing own product advantage and service advantage adequately. High-quality communication with the public can be achieved through network. Own products and marketing strategies also can be adjusted constantly when public needs are comprehended.

Secondly, network research of new high-tech enterprises should be strengthened appropriately because products and services relating to many new and high technology are time-based. Even some contents can not be comprehended by the public within short period of time. The gap between market demand and enterprises can be actually understood through the mode of research only. They can firmly control chances in the market, and try to provide valuable products for the tourists as far as possible. Specifically, enterprises shall send the designed questionnaire to clients through E-mail, WeChat friend circle and other form during the process of network research. The research scope can be expanded constantly through forwarding and click reward forms. After questionnaires are collected back, related management personnel should utilize database and other management software for sorting and analysis. On the basis, enterprise long-term business strategy can be formulated (figure 2). 


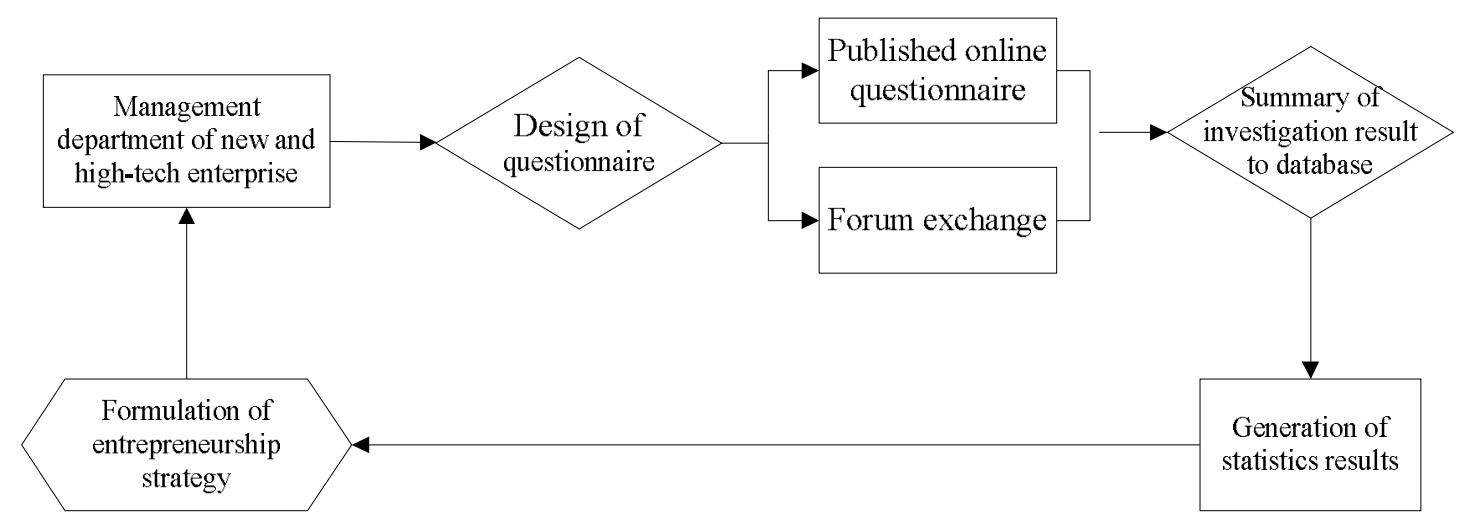

Figure 2 Flow chart of network research of travel agencies

\section{Brand building strategy}

In recent years, people's consumption level is rising, and their consumption decision-making has more rational characteristics, the demand on high-tech products is more diversified and refined. It is objectively required that new high-tech enterprises should continuously introduce new products, thereby meeting the needs of consumers. In the process, brand building is an indispensable and important segment. Current situation shows that some enterprises in China have integrated brand strategy into enterprise long-term development strategic objectives, and brand marketing methods are explored actively. In addition, the practice is enough to prove that enterprises are constantly guided for realizing rational development by active exploration of the enterprises. More enterprises realize that core competitiveness of enterprises can be improved effectively through shaping sound service brand.

Some specific brand name and standard given by enterprises to products or services are mainly emphasized aiming at brand management strategy. Brand connotations consistent with them are determined. Then, brand connotation is transferred to consumers in the market through proper marketing channels, and consumers can recognize and identify the connotation, thereby promoting consumption and repeated consumption. The process is regarded as brand management strategy. Related theory data and previous practice experience are combined. The author believes that brand building strategy of new high-tech enterprises is shown as follows (as shown in figure 3).

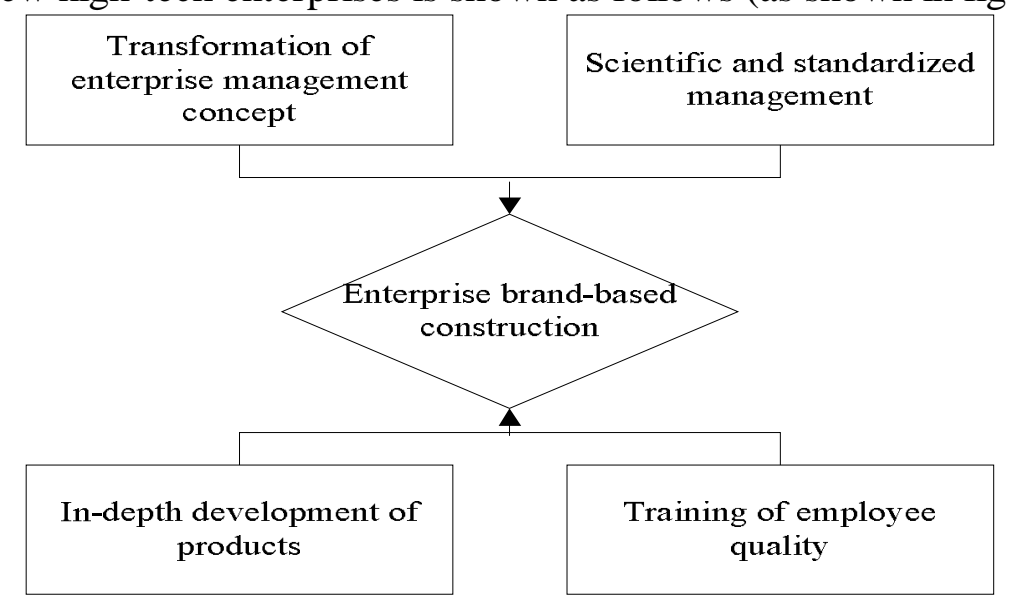

Figure 3 Brand building strategy of new high-tech enterprises

\section{Management innovation strategy of new high-tech enterprises}

Innovation is not merely is responsibility of research and development departments, which also penetrates through all aspects of normal operation management of enterprises. First of all, management departments shall support innovation activities. New high-tech enterprise activities can be implemented under the responsibility of person in charge of management. In addition, they still should be supported by specific innovation department. Therefore, innovation activities of new high-tech enterprises can be emphasized fully, and it can become an important department in normal operation process of enterprises. New high-tech enterprises generally have higher risk. Once the innovation is failed, it is likely to produce higher risks. Therefore, management department and innovation department should provide necessary support to help the enterprises to get out of budget deficiency or material shortages 
and other obstacles. Innovation core teams and other department personnel are encouraged actively for free combination.

Secondly, the human resources department should strengthen the guarantee role on innovation activities. Related personnel should be trained and developed in the aspects of innovation ability, management ability and leadership ability in new high-tech enterprises; thereby they can realize knowledge updating and skill optimization. For example, enterprises can establish one fair platform; therefore each personnel can obtain development chance. Certain award can be given aiming at some employees with prominent performance.

In addition, culture construction of new high-tech enterprises is the intangible asset of enterprises. It is the lifeblood for enterprises to realize long-term development. Culture construction is related to both enterprise internal culture and enterprise foreign brand culture from the systematic perspective. It can assist cohesion of internal employees of enterprises from the former perspective, and assist enterprises in image promotion from the later perspective.

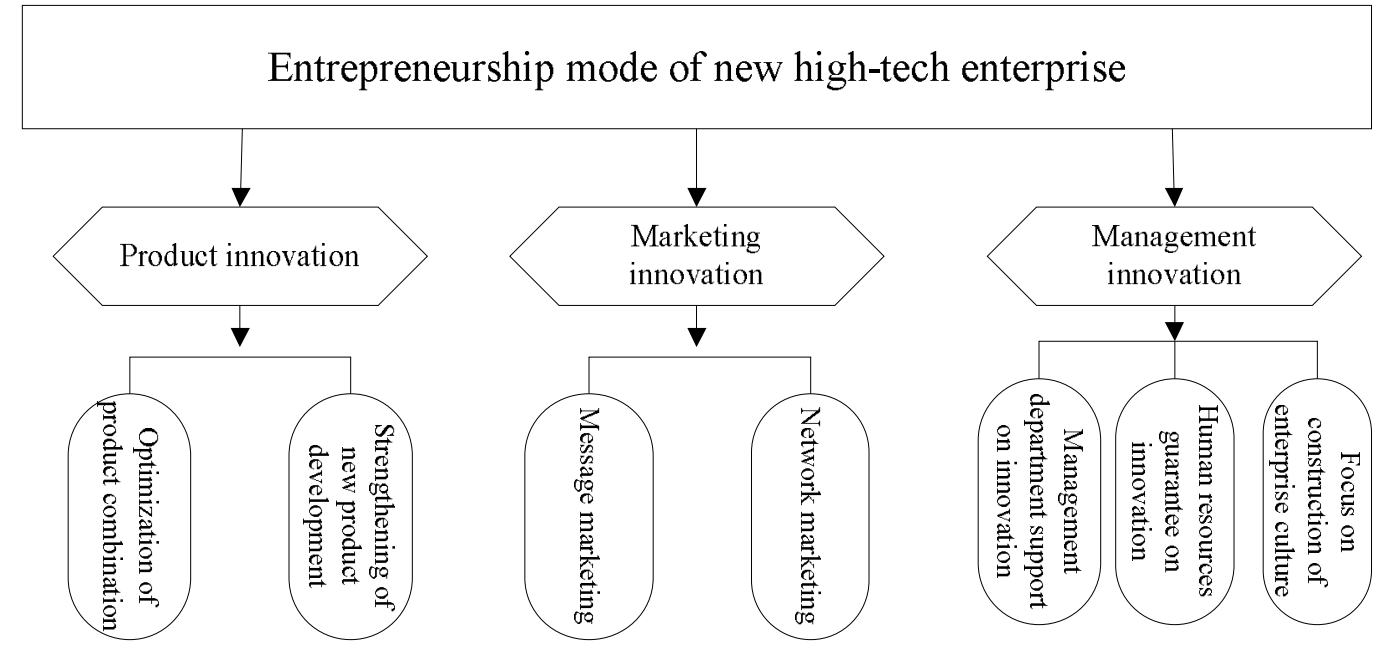

Figure 4 Innovation development of new high-tech enterprises

\section{Marketing and innovation strategy of new high-tech enterprises \\ Message marketing}

Solution of space problem is the most important in the process of information transmission. High and new technology industry is the product of information age. Therefore, it can be concluded that it is obtained from information, which also should be returned to information. Concretely, new high-tech enterprise can establish contact relationship with enterprise messaging service provider. Its universality, convenience, fast speed, dispersion and other characteristics therefore can be utilized for promotion for products in the enterprises. Therefore, the distance between enterprise and clients can be shortened, which is beneficial for improving client satisfaction and loyalty.

\section{Network marketing}

Network marketing has obvious advantages as an innovation of new generation, which not only has relatively flexible technique of expression, but also has the characteristics of web page design, namely combination of graphic and text. The cost is lower; network can be utilized for multidirectional communication. It is attractive with stronger conviction. In addition, more and more network users participate in network activities with constant expansion of network coverage area; therefore enterprise participation in network marketing has extremely important significance.

\section{Relationship marketing}

People orientation is the key for many enterprises to realize strategic development. The so-called relationship marketing refers that a long-term strategic partnership is established and maintained between enterprises and clients. Both parties relay on the established long-term cooperation relationship for obtaining corresponding income under relationship marketing. Internal employees of the enterprises can be arranged for specially engaging in effective communication and contact with related objects, thereby further promoting relationship and demand with clients. 


\section{Conclusion}

Generally speaking, the author summarizes present situation of new high-tech enterprise entrepreneurial management in China based on related theoretical basis and practical experience in the research of the paper. Corresponding development strategies are proposed. Enterprise management personnel should realize important significance of entrepreneurial management mode profoundly. Dynamic entrepreneurial management mode should be constructed from the perspectives of human resources, innovation, marketing, etc. It is also profoundly related to future development of enterprises.

\section{References}

[1] Su Xiaohua, Li Qianqian, Wang Ping. Influence of entrepreneurial orientation on performance of new high-tech enterprises-based on adjustment role of strong and weak relationship. Soft Science, 2013,01:10-14 + 19 .

[2] Tang Yong. Network closing, bridge connection and entrepreneurial team performance- empirical study based on Changsha new high-tech enterprise entrepreneurial team. Hunan Social Science, 2013,01:183-187.

[3] Mei Deqiang, Long Yong. Research on relationship among new high-tech enterprise entrepreneurship ability, innovation type and financing mode. Management Review, 2012,01:67-74.

[4] Fan Hong, Wang Min, Pan Yueqi. Venture investment promotion of growth of new high-tech enterprises: the function of financial support and the support. Science and Technology Progress and Countermeasure, 2012, 11:1-4.

[5] Wang Xiufeng, Li Huajing, Li Yonghui. Study on the relationship between green entrepreneurial orientation and enterprise performance-based on Zhongguancun new high-tech enterprises. Soft Science, 2015,06:42-45.

[6] Li Xiang. Research on entrepreneurial management mode of high and new technology enterprises. Jiangsu Business Theory, 2015 (27): 130-131.

[7] Han Yu, Guo Wenna. On construction of micro-entrepreneurship management mode of college students -with Zhiguang Company as an example. Management Personnel, 2015 (33).

[8] Wang Youyou. Research on innovation enterprise management mode. Science and Technology Entrepreneurs, 2014 (2).

[9] Yun Lexin, Yang Jun, Zhang Yuli. Generation mechanism based on returnee entrepreneurial enterprise innovative business prototype. Journal of Management, 2014, 11(3):367-375.

[10] Guo Hai, Shen Rui. How to convert entrepreneurial opportunities into enterprise performance intermediary role of commercial mode innovation and adjustment role of market environment. Economic Theory and Economic Management, 2014 (3):70-83. 